\title{
Celecoxib in arthritis: relative risk management profile and implications for patients
}

This article was published in the following Dove Press journal:

Therapeutics and Clinical Risk Management

6 November 2009

Number of times this article has been viewed

\author{
Gayle McKellar' \\ Gurkirpal Singh ${ }^{2}$ \\ 'Centre for Rheumatic Diseases, \\ Glasgow Royal Infirmary, Glasgow, \\ UK; ${ }^{2}$ Division of Gastroenterology \\ and Hepatology, Stanford University \\ School of Medicine, Palo Alto, \\ CA, USA
}

\begin{abstract}
Celecoxib is a selective cyclo-oxygenase 2 inhibitor licensed for use in musculoskeletal symptoms as well as in primary dysmenorrhea and acute pain. One advantage celecoxib has over traditional nonsteroidal anti-inflammatory drugs is that of significantly fewer gastrointestinal side-effects associated with its use. Much has been published on the potential cardiovascular and cerebrovascular complications of its administration. This review details the available evidence to allow prescribers to make informed decisions in the light of potentially conflicting evidence. The overall cardiovascular risk is increased with higher doses of celecoxib but is comparable with nonselective nonsteroidal anti-inflammatory use. As with all of these drugs, the potential cardiovascular and gastrointestinal risks of prescription need to be weighed up against possible benefits for each individual patient and discussed with the patients themselves.

Keywords: arthritis, cardiovascular, celecoxib, gastrointestinal, nonsteroidal anti-inflammatory drugs, safety
\end{abstract}

\section{Introduction}

Celecoxib (Celebrex ${ }^{\circledR}$; Pfizer Inc.) was the first selective cyclo-oxygenase (COX) 2 inhibitor to be used in everyday clinical practice. It is approved for use for musculoskeletal symptoms in osteoarthritis (OA), rheumatoid arthritis (RA) and ankylosing spondylitis, as well as in the management of primary dysmenorrhea and acute pain. The advantages for selective COX2 inhibitor use has been well-documented in the literature; similar efficacy to nonsteroidal anti-inflammatory drugs (NSAIDs) but with less gastrointestinal (GI) side-effects. Celecoxib was the first of many selective COX2 inhibitors most of which have now been withdrawn from clinical use (lumiracoxib rofecoxib and valdecoxib) because of concerns of serious side-effects. This review will discuss the evidence for the potential benefits of celecoxib use as well as scrutinizing the studies which detail its possible deleterious effects.

\section{Clinical effectiveness in treating arthritis}

Multiple clinical trials have demonstrated that celecoxib has similar efficacy as nsNSAIDs in the management of pain and inflammation, both acute and chronic. Emery et al in $1999^{1}$ studied the efficacy of celecoxib in patients with RA. Three hundred twenty-six patients received celecoxib $200 \mathrm{mg}$ twice daily and 329 received diclofenac, a NSAID, $75 \mathrm{mg}$ twice daily for 24 weeks. There was no documented difference between the 2 drugs for physician's assessment, patient assessment, number of swollen or tender joints, visual analogue scale (VAS) pain score, early morning stiffness, or C-reactive protein (CRP). The mean number of swollen and tender joints
Correspondence: Gayle McKellar Specialist Registrar in Rheumatology, Centre for Rheumatic Diseases, Glasgow Royal Infirmary, Castle Street, Glasgow G4 OSF, UK

Email gaylemckellar@nhs.net 
did however decrease over the course of the study. ACR-20 response at 24 weeks was scored as $25 \%$ in the celecoxib group and $22 \%$ in the diclofenac group. This paper was one of the initial studies to give credence to the use of celecoxib where traditional NSAIDs would have been used for the treatment of arthritis symptoms. In the same year a second group ${ }^{2}$ undertook a randomized, placebo-controlled, double-blind trial with approximately 200 patients in each arm. Placebo was compared with naproxen $500 \mathrm{mg}$ twice daily, celecoxib $100 \mathrm{mg}$ twice daily, $200 \mathrm{mg}$ twice daily, or $400 \mathrm{mg}$ twice daily. Celecoxib produced a significant improvement in signs and symptoms of RA for all efficacy measures with maximal effects by 2 weeks and comparable with the benefits seen with naproxen. Withdrawals for treatment failure were lower for all active therapy groups than for placebo $(P<0.001)$.

A few years later, Deeks et $\mathrm{al}^{3}$ performed a systematic review of the efficacy of celecoxib compared with another nonselective (ns) NSAID or placebo. Over 15,000 patients with either OA or RA who had received at least 12 weeks of therapy were identified. Efficacy was measured by the WOMAC score (Western Ontario and McMaster Osteoarthritis Index) and tolerability by rates of withdrawal for adverse events. Celecoxib and NSAIDs were equally effective for all efficacy outcomes. There were far fewer withdrawals in those taking celecoxib than other NSAIDs for GI side-effects.

A recently published review of celecoxib assessed the clinical and cost- effectiveness of selective COX2 inhibitors and NSAIDs for OA and RA treatment. ${ }^{4}$ Forty randomized controlled trials involving celecoxib compared to placebo, other selective COX2 inhibitors, or nonselective (ns) NSAIDs were identified. Compared with nsNSAIDs, celecoxib was equally efficacious and of superior GI tolerability. The base-case incremental cost per quality adjusted life year (QALY) results for celecoxib versus diclofenac was $£ 151,000$.

\section{Celecoxib and the upper gastrointestinal system}

The GI toxicity of traditional NSAIDs is due to the nonselective inhibition of both COX1 and COX2 isoenzymes involved in prostaglandin synthesis. ${ }^{5}$ Selective COX2 inhibitors were developed to suppress prostaglandin production by the COX2 enzyme selectively, consequently, giving anti-inflammatory and analgesic benefits while protecting the gastroprotective activity of COX1. The clinical adverse GI effects of NSAIDs are well known. Clinical symptoms are poor predictors of actual gastrointestinal injury. Anti-inflammatory drug-induced peptic ulcers are frequently asymptomatic. Patients taking traditional NSAIDs were previously said to be 5 to 7 times more likely to be hospitalized for a GI complication than nonusers. ${ }^{6,7}$

One of the first studies on the potential lesser upper GI effects of celecoxib was published in $1999 .{ }^{2}$ Patients with RA were randomized to one of three differing doses of celecoxib (100 mg, $200 \mathrm{mg}$ or $400 \mathrm{mg}$ twice daily), naproxen or placebo. All doses of celecoxib were seen to have a reduced frequency of endoscopic ulcers than naproxen, the comparative NSAID in this study. Emery et al ${ }^{1}$ demonstrated significantly reduced reporting of abdominal pain, gastric ulceration and duodenal ulceration when celecoxib was compared with diclofenac ( $P<0.05, P<0.001$, and $P<0.009$, respectively).

The celecoxib long-term arthritis safety study (CLASS) was a large double-blind randomized controlled trial. Patients with $\mathrm{OA}$ or RA were randomized to receive celecoxib $400 \mathrm{mg}$ twice daily $(\mathrm{n}=3987)$, ibuprofen $800 \mathrm{mg} 3$ times daily $(n=1985)$ or diclofenac $75 \mathrm{mg}$ twice daily $(\mathrm{n}=1996) .{ }^{8}$ Initial data (at 6 months follow up) suggested that rates of symptomatic GI ulcers and ulcer complications were significantly lower with celecoxib compared with NSAIDs. However, full study results, when made available, showed that there was no difference at 1 year. The CLASS study had a high-dropout rate at 1 year which made the interpretation of these results somewhat difficult.

In 2002, Mamdani et $\mathrm{al}^{9}$ performed a retrospective observational cohort study to compare rates of upper GI hemorrhage in elderly patients prescribed NSAIDs and selective COX2 inhibitors who were previously anti-inflammatory naïve. They found no increased short-term risk with celecoxib (adjusted rate ratio 1.0, 95\% confidence interval [CI] 0.7 to 1.6), unlike NSAIDs and rofecoxib. The risk of upper GI hemorrhage with celecoxib was similar to that of controls not using NSAIDs. Singh et $\mathrm{al}^{10}$ compared the GI side-effects of celecoxib with diclofenac and naproxen in a double-blinded, randomized clinical trial of over 13,000 patients (SUCCESS-I). Significantly more ulcer complications were seen in the NSAID than celecoxib group $(0.8 / 1000$-person years versus $0.1 / 1000$-person years, odds ratio [OR] 7.02, $P=0.008$ ).

van der Linden et $\mathrm{al}^{11}$ performed a nested case-control study of a historical cohort of patients in The Netherlands to assess the incidence of first hospitalization for GI events in patient prescribed traditional NSAIDs and selective COX2 inhibitors (incorporating gastric and duodenal ulcers, ulceration of GI tract, gastritis, duodenitis, and GI hemorrhage). Adjusted OR for any GI with celecoxib therapy was 1.36 (95\% CI 0.70 to 2.66). When compared with celecoxib, unsurprisingly, the risk was much higher with 
the traditional NSAIDs, naproxen (OR 3.26, 95\% CI 1.59 to 6.70) and diclofenac (OR 3.50, 95\% 1.76 to 6.98).

Management difficulties can arise when patients are admitted with a GI bleed but require anti-inflammatory management for musculoskeletal symptoms. Chan et al published on recurrent ulcer bleeding rates in patients subsequently given celecoxib, who were initially admitted with upper GI bleeding while on a traditional NSAID for arthritis treatment. ${ }^{12}$ Patients were either given celecoxib plus placebo or esomperazole, a proton-pump inhibitor (PPI). The combination group had a significantly reduced incidence of upper GI bleeding: 0 vs $12 \%, P=0.0004,95 \%$ CI 4.1 to 13.7 .

\section{Potential prevention of colorectal malignancies with celecoxib}

The APC study investigators investigated the potential benefits of celecoxib on reducing colorectal adenomatous polyps and cancer. ${ }^{13}$ This was on the basis that selective COX2 inhibitors had been shown to reduce the number of colorectal adenomas in animals, as well as that the over expression of COX2 had been associated with colorectal adenomatous polyps and cancer. Patients who had previously had adenomas removed were randomized to placebo, celecoxib $200 \mathrm{mg}$ twice daily or $400 \mathrm{mg}$ twice daily. The estimated cumulative incidence of detection of adenomas at year 3 was $43.2 \%$ in the $200 \mathrm{mg}$ twice daily group (risk ratio [RR] 0.67, 95\% CI 0.59 to $0.77, P<0.001$ ) and $37.5 \%$ in the $400 \mathrm{mg}$ twice daily group (RR $0.55,95 \%$ CI 0.48 to $0.64, P<0.001$ ) compared with placebo. For advanced adenomas in the two treatment groups the estimated cumulative incidence was $7.8 \%$ (RR $0.43,95 \%$ CI 0.31 to $0.61, P<0.001$ ) and $6.3 \%$ (RR 0.34 , $95 \%$ CI 0.24 to $0.50, P<0.001$ ) respectively.

In the same issue of the NEJM, the PreSAP trial investigators reported their randomized placebo controlled trial. They demonstrated that the use of $400 \mathrm{mg}$ celecoxib once daily significantly reduced the occurrence of colorectal adenomas within the 3 years after a polypectomy (relative risk $0.64,95 \%$ CI 0.56 to $0.75 P<0.001) .{ }^{14}$

\section{Potential hepatic side-effects}

A number of individual case reports have been published detailing hepatoxicity secondary to celecoxib treatment. ${ }^{15-17}$ More impressive however are the published data on largerscale investigatory groups such as the CLASS study where nearly 4000 patients took celecoxib at $800 \mathrm{mg} /$ day without any significant elevation in aminotransferases compared with traditional NSAID. ${ }^{8}$ Importantly, the SUCCESS-1 study showed that the occurrence of transaminitis was much lower with celecoxib than with nsNSAIDs, $0.5 \%$ versus $1.3 \%$ $(P<0.001) .{ }^{10}$ The FDA and WHO published a case/noncase analysis of spontaneous reports of hepatotoxicity of COX2s versus nsNSAIDs. The authors concluded that there was no increased safety concerns for celecoxib compared with NSAIDs, unlike diclofenac and nimesulide. ${ }^{18}$ While we should be alert to the potential development of abnormal liver function while a patient is taking celecoxib, the major studies do not show any noteworthy trend.

\section{Celecoxib and acute myocardial infarction}

Concern was initially raised of the potential cardiovascular (CV) toxicity of selective COX2 inhibitors and NSAIDs was raised by the publication of data from the VIGOR trial by Bombardier et $\mathrm{al}^{19}$ The $\mathrm{CV}$ risk of rofecoxib at that time was explained by being artefactual because of a presumed cardioprotective benefit of naproxen. Subsequent observational studies proved that this could not be true. ${ }^{20}$ The first firm evidence demonstrating the increased risk of selective COX2 inhibitors compared with placebo was the APPROVe trial in 2004. ${ }^{21}$ The results of this trial confirmed many previous observational studies on the $\mathrm{CV}$ risks of rofecoxib and lead to the withdrawal of the drug. Subsequently, the APC ${ }^{13}$ and Pre-SAP ${ }^{14}$ studies showed that at high doses, celecoxib can also increase the risk of $\mathrm{CV}$ complications when compared to placebo.

The risk of high doses of celecoxib was confirmed in a pooled analysis published by Solomon et al. ${ }^{22}$ The data from 7950 patients enrolled in 6 placebo-controlled trials of celecoxib was analyzed. There was a clear increased risk of all CV events including acute myocardial infarction (AMI) with increasing doses of celecoxib $(P=0.0005)$. It should be noted that the patients in these studies had conditions other than arthritis. Many observational studies have shown that the increase in risk is not limited to celecoxib, but indeed is present with most nsNSAIDs ${ }^{23}$ and that the risk with celecoxib may be of smaller magnitude than most other NSAIDs. ${ }^{24}$ There are a large number of observational studies in publication in which these conclusions are also borne out. ${ }^{4,11,25-30}$

As mentioned previously, a large amount of data related to celecoxib and AMI is available from studies investigating the potential benefits in colorectal neoplasia prevention. The first data were published by Solomon et al in 2005. ${ }^{31}$ Deaths from CV causes and nonfatal AMI numbered 27 in patients exposed to celecoxib, calculated hazard ratio (HR) 
3.4 (nonfatal AMI alone numbered 18). A further paper published by Bertagnolli et $\mathrm{al}^{13}$ the following year analyzed CV "disorders", encompassing a variety of conditions including AMI, angina, cerebrovascular disease, and circulatory collapse. RR in the whole group for low-dose celecoxib was 1.5 , compared with 1.8 in higher doses.

The much referenced systematic review and meta-analysis from $\mathrm{McGettigan}$ and Henry ${ }^{24}$ analyzed the risk of serious CV events with selective COX2 inhibitor therapy. They found that celecoxib was not associated with an increased risk of vascular occlusion (summary RR 1.06, 95\% CI 0.91 to 1.23). This compares with summary RR of 1.33 for low-dose rofecoxib (95\% CI 1.00 to 1.79), 2.19 for high-dose rofecoxib (95\% CI 1.64 to 2.91), 1.40 for diclofenac (95\% CI 1.16 to 1.70), 1.07 for ibuprofen (95\% CI 0.97 to 1.18$)$, and 0.97 for naproxen (95\% CI 0.97 to 1.18$)$.

As detailed from the many published works on this topic, the data on potential increased cardiovascular risk for patients taking celecoxib are inconsistent. It would seem clinically appropriate for the decision on prescription to be made on a patient by patient basis taking into account the individual's $\mathrm{CV}$ history and risk profile, and with regular reviews of the need for therapy. While inconsistent, the evidence most likely points to an increase in risk of AMI with celecoxib compared to placebo when doses of at least $400 \mathrm{mg}$ are used. No clinical trials have been able to show an increased risk when $200 \mathrm{mg}$ /day or less is used, although this does not rule out such an effect in susceptible patients. The increased risk does not seem to be out of proportion to the risk seen with nsNSAIDs.

\section{Celecoxib and heart failure}

Anti-inflammatory drugs can be associated with a degree of fluid retention through an increased cortical expression of COX2. Mamdani's population-based retrospective cohort study $^{32}$ assessed nearly 19000 NSAID-naïve patients who were commenced on celecoxib. Less than $1 \%$ developed congestive heart failure (CHF) within 6 months of commencement (identical to nonNSAID control group) and approximately $6 \%$ developed CHF over a 5 -year period (not significant compared to the control group).

A population-based retrospective cohort study studied 2256 patientsagedover66whowereprescribedNSAID, rofecoxib or celecoxib after an index admission for $\mathrm{CHF}^{33}$ Crude event rates for recurrent $\mathrm{CHF}$ per 100 person-years were calculated and showed a difference between selective COX2 inhibitors (celecoxib 27.6, rofecoxib 32.4) and NSAIDs (24.4). Within the Colorectal Adenoma Prevention trial $^{31}$ the number of nonfatal heart failure events with the placebo group $(n=2,0.3 \%)$ was comparable to the events in the celecoxib $200 \mathrm{mg}$ bd group ( $\mathrm{n}=1,0.1 \%$ ). A case control study of patients admitted with congestive cardiac failure ${ }^{34}$ identified 25 first admissions in patients prescribed celecoxib. Two of these patients had taken less than $600 \mathrm{mg}$ celecoxib in the week prior to admission, 15 had taken between 601 and $1400 \mathrm{mg}$ celecoxib, and 4 taken greater than $1400 \mathrm{mg}$. Multivariate analysis and comparison with controls showed a weak and statistically nonsignificant association between celecoxib use and hospitalization for CHF (OR 1.47, 95\% CI 0.86 to 2.53, $\mathrm{P}=0.160)$ - this was also seen for rofecoxib and other traditional NSAIDs.

\section{Potential renal side-effects}

The physiological interactions between COX2 and the renal system is complex. Increased cortical expression of COX2 is seen with sodium depletion, aortic coarctation, CHF, loop diuretic therapy and Bartter's syndrome amongst others. COX2 expression is specifically linked to the renin-angiotensin system (RAS) and causes activation of this pathway. Decreased RAS activity causes increased COX2 expression and vice versa. COX2 is known to have critical roles at the cortical thick ascending limb of the loop of Henle, macula densa and in the medullary interstitium. ${ }^{35}$ There is case-report documentation of renal side-effects secondary to celecoxib use, ${ }^{17}$ but much more robust data are available from a number of large-scale studies and reviews.

A randomized crossover trial of celecoxib with naproxen as the comparator looked specifically at renal function outcomes in an elderly population. ${ }^{36} \mathrm{~A}$ comparable reduction in glomerular filtration rate was seen for both naproxen and celecoxib and therefore the selective COX2 inhibitor was not felt to be any more nephrotoxic. Similarly, the CLASS study did not show any significant elevation in serum creatinine in nearly 4000 celecoxib users when compared with NSAID users (ibuprofen or diclofenac). ${ }^{8}$ Zhang et al published a large meta-analysis of 114 randomized, double-blind controlled trials of selective COX2 inhibitors, within which 37 celecoxib trial populations were identified. ${ }^{37}$ The RR of developing renal dysfunction with celecoxib was 0.61 (95\% CI 0.4 to 0.94 ) compared with controls. No between-treatment difference in creatinine clearance or serum electrolytes was seen in a double-blind, placebo-controlled study of 85 patients assigned to naproxen, etoricoxib, or celecoxib. ${ }^{38}$ 
As per prescribing guidelines, the use of celecoxib and NSAIDs is contra-indicated in patients with pre-existing renal impairment. The prescribing physician should remain alert to the development of abnormal renal function in a patient prescribed celecoxib, but its use is not associated with any increased nephrotoxicity compared with traditional NSAIDs.

\section{Blood pressure effects of celecoxib}

The effects of the addition of celecoxib on blood pressure (BP) control in patients on angiotension-converting enzyme inhibitors for hypertension has been studied via 24-hour ambulatory BP monitoring. ${ }^{39}$ Doses of celecoxib $200 \mathrm{mg}$ twice daily made no difference on the anti-hypertensive effect of lisinopril. Wolfe et al have published data on the association of NSAID use with hypertension. ${ }^{40}$ In normotensive and hypertensive patients, there was no increased OR of higher documented BP with celecoxib. This was not the case for rofecoxib. Zhang's meta-analysis also failed to show any increased RR of hypertension with celecoxib therapy: $0.83 .{ }^{37}$

A number of meta-analyses have scrutinized the potential evidence connecting celecoxib with a rise in blood pressure. Aw et al published a meta-analysis in 2005 of 19 randomized control trials, which included 8 celecoxib trial populations. ${ }^{41}$ Weighted mean differences (WMD) of systolic and diastolic BPs were calculated. Overall, a disproportionate increase in systolic rather than diastolic BP was seen with all nsNSAIDs. The overall RR of developing hypertension for celecoxib compared with placebo was not statistically significant (0.81, 95\% CI 0.13 to 5.21$)$. These data on hypertension compares well with the only other selective COX2 inhibitor still on the market, etoricoxib.

The CRESCENT investigators, lead by Sowers, did not show any difference with celecoxib on 24-hour ambulatory BP control in known hypertensives. ${ }^{42}$ However, the proportion of patients with controlled blood pressure at baseline who developed worsening of BP by week 6 was documented as $16 \%$ in the celecoxib arm $(P=0.05)$, indicating that like all NSAIDs, BP monitoring is advised whenever treatment is initiated with celecoxib. Bertagnolli's work on the potential role in colorectal adenoma prevention of celecoxib documented some blood pressure data. ${ }^{13}$ There was no significant increased RR of developing hypertension in the cohort and aspirin co-prescription made no difference. In contrast, Schwartz et al demonstrated a significant increase in ambulatory systolic BP with etoricoxib $90 \mathrm{mg}$ once daily compared with celecoxib $200 \mathrm{mg}$ twice daily and naproxen $500 \mathrm{mg}$ twice daily $(P<0.05) .{ }^{38}$ Additionally, recently published data from the MEDAL study documented an increase in systolic BP (average rise of 3.4 to $3.6 \mathrm{mmHg}$ ) with etoricoxib therapy. ${ }^{43}$

\section{Celecoxib and stroke}

Within the Colorectal Adenoma Prevention trial, ${ }^{31}$ the number of nonfatal strokes with the placebo group was identical to the events in the celecoxib $200 \mathrm{mg}$ twice daily group ( $\mathrm{n}=3,0.4 \%)$, compared with 5 events $(0.7 \%)$ in the celecoxib $400 \mathrm{mg}$ twice daily group. Solomon et al's cohort study of over 26,000 celecoxib users in the Medicare program identified 988 strokes and an adjusted RR of 1.00 (95\% CI 0.92 to 1.09$){ }^{29}$

A landmark study from Andersohn and colleagues assessed nearly 500,000 patients on the UK GP research database between 2000 and $2004^{44}$ to identify the risk of ischemic stroke with NSAID or selective COX2 inhibitor use. No increased risk was found with current celecoxib use (multivariate OR 1.07). An increased risk was seen with rofecoxib and etoricoxib (OR 1.71 and 2.38, respectively). As per the AMI data, a dose-dependent effect was seen. Celecoxib at $\leq 200 \mathrm{mg} /$ day was associated with a multivariate OR 0.97 (95\% CI 0.71 to 1.32 ) and $>200 \mathrm{mg} /$ day was associated with a multivariate OR 1.20 (95\% CI 0.46 to 3.11 ). Etoricoxib at $\leq 60 \mathrm{mg}$ /day was associated with a much higher multivariate OR 2.04 (95\% CI 0.87 to 4.80$)$ and $>60 \mathrm{mg} /$ day was associated with a multivariate OR 3.27 (95\% CI 0.59 to 18.16). It is possible that these differences in stroke rates between celecoxib and etoricoxib reflect the differential effect on hypertension of these drugs.

Lee et $\mathrm{a}^{45}$ reviewed the impact of celecoxib prescription on cerebrovascular disease incidence in patients with and without documented coronary artery disease (CAD). There was no increased risk of cerebrovascular event in the group without CAD prescribed celecoxib (OR 0.97, 95\% CI 0.68 to 137). However, there was an increased risk of events in those with pre-existing CAD prescribed celecoxib (OR 1.40, 95\% CI 0.96 to 2.03). A recently published study based on data from the population-based Rotterdam study ${ }^{46}$ assessed HR for ischemic stroke with NSAID and selective COX2 inhibitor prescription. Only 1 event was documented in celecoxib users and therefore there was no significant outcome.

Nadareishvili et $\mathrm{al}^{47}$ performed a nested case control analysis to determine the risk of stroke in patients with RA. Two hundred sixty-nine patients with first-ever stroke were identified, including 41 in patients with RA. The OR for 
ischemic stroke in RA was 2.66 (95\% CI 1.24 to $5.70, P=$ 0.012). Adjusted for cardiovascular, RA risk factors, and other co-variants, ischemic stroke was significantly associated with rofecoxib use (OR 3.66, $P=0.27$ ), but not significantly with celecoxib (OR 2.65, $P=0.051$ ). A recently published retrospective cohort study of over 300,000 Medicaid patients in Tennessee over a 5 -year period ${ }^{48}$ documented 4354 stroke admissions. Of these, 144 were patients who were prescribed celecoxib. Compared with nonusers of selective COX2 inhibitors or NSAIDs, the adjusted HR for stroke was only 1.04 (95\% CI 0.87 to 1.23$)$. A slightly higher HR of 1.12 (95\% CI 0.83 to 1.52$)$ in new users of celecoxib was documented.

\section{Effects of co-prescription of celecoxib and aspirin}

The benefit of aspirin in the primary and secondary prevention of $\mathrm{CV}$ events is well established. As the prescription rates for aspirin will continue to climb, the number of patients potentially prescribed this as well as an anti-inflammatory drug will too.

Wilner et $\mathrm{al}^{49}$ published a double-blind, placebo-controlled trial of 16 healthy volunteers assigned to celecoxib $400 \mathrm{mg}$ daily or placebo for 4 days. Aspirin $325 \mathrm{mg}$ plus celecoxib $200 \mathrm{mg}$ or placebo was prescribed on day 5 . No significant difference in thromboxane inhibition between the 2 groups was noted. There was also no significant difference in the effect of aspirin on platelet aggregation due to ADP, collagen, or arachidonic acid between the groups. The groups summarized that celecoxib does not have an effect on the aspirin effects of platelet function. This is an important consideration in the selection of NSAIDs in patients on low-dose aspirin since, unlike celecoxib, several nsNSAIDs have been shown to cause pharmacodynamic interference with the anti-platelet effect of aspirin.

The population impact of any possible interaction is potentially large. In a sample of the general population prescribed selective COX2 inhibitors, analyzed by Cox et $\mathrm{al}^{50} 48 \%$ were co-prescribed aspirin, $43 \%$ paracetamol, and, interestingly, $10 \%$ also were prescribed a nonselective NSAID. Unsurprisingly, the use of aspirin increased with increasing patient age.

Levesque $^{51}$ documented the RR of first AMI in a cohort of over 113,000 elderly patients. Patients prescribed celecoxib with or without aspirin were identified. There was no significant difference in adjusted RR of AMI in those who were or were not prescribed aspirin alongside celecoxib. This differs from the low-dose rofecoxib group who showed a significantly reduced risk of AMI if prescribed aspirin - the same was not true for patients on high-dose rofecoxib. It must be pointed out that the actual number of patients who had an AMI while on aspirin was small and conclusions drawn from this study should be guarded. Rahme et al found that the combination of celecoxib and aspirin was less likely to be associated with hospitalization for GI events than NSAIDs with aspirin (HR $0.62,95 \% 0.48$ to 0.80$).{ }^{52,53}$ In fact, hospitalization rates for GI events were similar for celecoxib plus aspirin as NSAID without aspirin (HR 1.01, 95\% CI 0.81 to 1.25 ). A limitation of the study was that over-the-counter data for aspirin were not available.

\section{Conclusion}

Celecoxib continues to be an effective and valuable alternative to traditional NSAIDs in the treatment of acute and chronic pain. The superior GI tolerability is well-documented and compelling. Data on potential increased CV risk for patients taking celecoxib are inconsistent, but do point to a small increase risk, especially when higher doses are prescribed. This risk is comparable with that of traditional nonselective NSAIDs.

As with all of these drugs, the potential CV and GI risks of prescription need to be weighed against possible benefits for each individual patient and discussed with the patient. If the CV risk increase with celecoxib is small and lower than that of most other NSAIDs, the concern would be of increasing the complications in a high $\mathrm{CV}$ risk patient if they were to be prescribed another NSAID. If such a high-risk patient must take aspirin, the argument for selective COX2 inhibitors is stronger as nsNSAIDs may block the effect of aspirin. Concomitant PPI use should be considered in these patients. As is the case with all anti-inflammatories, the prescription of celecoxib for an individual patient should be reviewed regularly and the lowest dose used for the shortest possible period of time.

\section{Disclosures}

The authors declare no conflicts of interest.

\section{References}

1. Emery P, Zeidler H, Kvien TK, Guslandi M, Naudin R, Stead H, et al. Celecoxib versus diclofenac in long-term management of rheumatoid arthritis: randomised double-blind comparison. Lancet. 1999;354(9196):2106-2111.

2. Simon LS, Weaver AL, Graham DY, Kivitz AJ, Lipsky PE, Hubbard RC, et al. Anti-inflammatory and upper gastrointestinal effects of celecoxib in rheumatoid arthritis: a randomized controlled trial. JAMA. 1999;282(20):1921-1928.

3. Deeks JJ, Smith LA, Bradley MD. Efficacy, tolerability, and upper gastrointestinal safety of celecoxib for treatment of osteoarthritis and rheumatoid arthritis: Systematic review of randomised controlled trials. BMJ. 2002;325(7365):619-623. 
4. Chen Y-F, Jobanputra P, Barton P, Bryan S, Fry-Smith A, Harris G, et al. Cyclooxygenase-2 selective non-steroidal anti-inflammatory drugs (etodolac, meloxicam, celecoxib, rofecoxib, etoricoxib, valdecoxib and lumiracoxib) for osteoarthritis and rheumatoid arthritis: A systematic review and economic evaluation. Health Technol Assess (Rockv). 2008;12(11):iii-158.

5. Meade EA, Smith WL, DeWitt DL. Differential inhibition of prostaglandin endoperoxide synthase (cyclooxygenase) isozymes by aspirin and other non-steroidal anti-inflammatory drugs. J Biol Chem. 1993;268(9):6610-6614.

6. Fries JF, Miller SR, Spitz PW, Williams CA, Hubert HB, Bloch DA. Toward an epidemiology of gastropathy associated with nonsteroidal antiinflammatory drug use. Gastroenterology. 1989;96(2 Pt 2 Suppl) 647-659.

7. Wolfe MM, Lichtenstein DR, Singh G. Gastrointestinal toxicity of nonsteroidal antiinflammatory drugs. N Engl J Med. 1999;340(24):18881899. [erratum in N Engl J Med. 1999;341(7):548].

8. Silverstein FE, Faich G, Goldstein JL, Simon LS, Pincus T, Whelton A, et al. Gastrointestinal toxicity with celecoxib vs nonsteroidal anti-inflammatory drugs for osteoarthritis and rheumatoid arthritis: the CLASS study: A randomized controlled trial. Celecoxib Long-term Arthritis Safety Study. JAMA. 2000;284(10): 1247-1255.

9. Mamdani M, Rochon PA, Juurlink DN, Kopp A, Anderson GM, Naglie G, et al. Observational study of upper gastrointestinal haemorrhage in elderly patients given selective cyclo-oxygenase-2 inhibitors or conventional non-steroidal anti-inflammatory drugs. BMJ. 2002;325(7365):624-627.

10. Singh G, Fort JG, Goldstein JL, Levy RA, Hanrahan PS, Bello AE, et al. Celecoxib versus naproxen and diclofenac in osteoarthritis patients: SUCCESS-I Study. Am J Med. 2006;119(3):255-266. [erratum in Am J Med. 2006;119(9):801].

11. van der Linden MW, van der Bij S, Welsing P, Kuipers EJ, Herings RMC. The balance between severe cardiovascular and gastrointestinal events among users of selective and non-selective non-steroidal anti-inflammatory drugs. Ann Rheum Dis. 2009;68:668-673.

12. Chan FK, Wong VW, Suen BY, Wu JC, Ching JY, Hung LC, et al. Combination of a cyclo-oxygenase-2 inhibitor and a proton-pump inhibitor for prevention of recurrent ulcer bleeding in patients at very high risk: a double-blind, randomised trial. Lancet. 2007;369(9573):1621-1626.

13. Bertagnolli MM, Eagle CJ, Zauber AG, Redston M, Solomon SD, Kim K, et al. Celecoxib for the prevention of sporadic colorectal adenomas. N Engl J Med. 2006;355(9):873-884.

14. Arber N, Eagle CJ, Spicak J, Racz I, Dite P, Hajer J, et al. Celecoxib for the prevention of colorectal adenomatous polyps. $N$ Engl J Med. 2006;355(9):885-895.

15. Galan MV, Gordon SC, Silverman AL. Celecoxib-induced cholestatic hepatitis. Ann Intern Med. 2001;134(3):254.

16. Grieco A, Miele L, Giorgi A, Civello IM, Gasbarrini G. Acute cholestatic hepatitis associated with celecoxib. Ann Pharmacother. 2002;36(12):1887-1889.

17. Tabibian JH, Tabibian N, Kaufman DM. Late-onset celecoxib-induced combined hepato-nephrotoxicity. $\mathrm{Br} \mathrm{J} \mathrm{Clin}$ Pharmacol. 2008;66(1):150-151.

18. Sanchez-Matienzo D, Arana A, Castellsague J, Perez-Gutthann S. Hepatic disorders in patients treated with COX-2 selective inhibitors or nonselective NSAIDs: A case/noncase analysis of spontaneous reports. Clin Ther. 2006;28(8):1123-1132.

19. Bombardier C, Laine L, Reicin A, Shapiro D, Burgos-Vargas R, Davis B, et al. Comparison of upper gastrointestinal toxicity of rofecoxib and naproxen in patients with rheumatoid arthritis. VIGOR Study Group. N Engl J Med. 2000;343(21):1520-1528.

20. Ray WA, Stein CM, Hall K, Daugherty JR, Griffin MR. Nonsteroidal anti-inflammatory drugs and risk of serious coronary heart disease: an observational cohort study. Lancet. 2002;359(9301): 118-123.
21. Bresalier RS, Sandler RS, Quan H, Bolognese JA, Oxenius B, Horgan K, et al. Cardiovascular events associated with rofecoxib in a colorectal adenoma chemoprevention trial. $N$ Engl J Med. 2005;352(11): 1092-1102. [erratum in N Engl J Med. 2006;355(2):221].

22. Solomon SD, Wittes J, Finn PV, Fowler R, Viner J, Bertagnolli MM, et al. Cardiovascular risk of celecoxib in 6 randomized placebo-controlled trials: the cross trial safety analysis. Circulation. 2008;117(16): 2104-2113.

23. McKellar G, Madhok R, Singh G. The problem with NSAIDs: what data to believe? Curr Pain Headache Rep. 2007;11(6):423-427.

24. McGettigan P, Henry D. Cardiovascular risk and inhibition of cyclooxygenase: a systematic review of the observational studies of selective and nonselective inhibitors of cyclooxygenase 2. JAMA. 2006;296(13):1633-1644

25. Andersohn F, Suissa S, Garbe E. Use of first- and second-generation cyclooxygenase-2-selective nonsteroidal antiinflammatory drugs and risk of acute myocardial infarction. Circulation. 2006;113(16):1950-1957.

26. Gislason GH, Jacobsen S, Rasmussen JN, Rasmussen S, Buch P, Friberg J, et al. Risk of death or reinfarction associated with the use of selective cyclooxygenase- 2 inhibitors and nonselective nonsteroidal antiinflammatory drugs after acute myocardial infarction. Circulation. 2006;113(25):2906-2913.

27. Graham DJ, Campen D, Hui R, Spence M, Cheetham C, Levy G, et al. Risk of acute myocardial infarction and sudden cardiac death in patients treated with cyclo-oxygenase 2 selective and non-selective nonsteroidal anti-inflammatory drugs: nested case-control study. Lancet. 2005;365(9458):475-481.

28. Helin-Salmivaara A, Virtanen A, Vesalainen R, Gronroos JM, Klaukka T, Idanpaan-Heikkila JE, et al. NSAID use and the risk of hospitalization for first myocardial infarction in the general population: a nationwide case-control study from Finland. Eur Heart J. 27(14):1657-1663.

29. Solomon DH, Avorn J, Sturmer T, Glynn RJ, Mogun H, Schneeweiss S. Cardiovascular outcomes in new users of coxibs and nonsteroidal antiinflammatory drugs: high-risk subgroups and time course of risk. Arthritis Rheum. 2006;54(5):1378-1389.

30. Hernandez-Diaz S, Varas-Lorenzo C, Garcia Rodriguez LA. Nonsteroidal antiinflammatory drugs and the risk of acute myocardial infarction. Basic Clin Pharmacol Toxicol. 2006;98(3):266-274.

31. Solomon SD, McMurray JJ, Pfeffer MA, Wittes J, Fowler R, Finn $\mathrm{P}$, et al. Cardiovascular risk associated with celecoxib in a clinical trial for colorectal adenoma prevention. $N$ Engl J Med. 2005;352(11):1071-1080.

32. Mamdani M, Juurlink DN, Lee DS, Rochon PA, Kopp A, Naglie G, et al. Cyclo-oxygenase-2 inhibitors versus non-selective non-steroidal antiinflammatory drugs and congestive heart failure outcomes in elderly patients: a population-based cohort study. Lancet. 2004;363(9423): 1751-1756.

33. Hudson M, Richard H, Pilote L. Differences in outcomes of patients with congestive heart failure prescribed celecoxib, rofecoxib, or non-steroidal anti-inflammatory drugs: population based study. $B M J$. 2005;330(7504):1370.

34. McGettigan P, Han P, Jones L, Whitaker D, Henry D. Selective COX-2 inhibitors, NSAIDs and congestive heart failure: differences between new and recurrent cases. Br J Clin Pharmacol. 2008;65(6):927-934.

35. Harris CJ, Brater DC. Renal effects of cyclooxygenase-2 selective inhibitors. Curr Opin Nephrol Hypertens. 2001;10(5):603-610.

36. Whelton A, Schulman G, Wallemark C, Drower EJ, Isakson PC, Verburg KM, et al. Effects of celecoxib and naproxen on renal function in the elderly. Arch Intern Med. 2000;160(10):1465-1470.

37. Zhang J, Ding EL, Song Y. Adverse effects of cyclooxygenase 2 inhibitors on renal and arrhythmia events: meta-analysis of randomized trials. JAMA. 2006;296(13):1619-1632.

38. Schwartz JI, Thach C, Lasseter KC, Miller J, Hreniuk D, Hilliard DA, et al. Effects of etoricoxib and comparator nonsteroidal anti-inflammatory drugs on urinary sodium excretion, blood pressure, and other renal function indicators in elderly subjects consuming a controlled sodium diet. J Clin Pharmacol. 2007;47(12):1521-1531. 
39. White WB, Kent J, Taylor A, Verburg KM, Lefkowith JB, Whelton A. Effects of celecoxib on ambulatory blood pressure in hypertensive patients on ACE inhibitors. Hypertension. 2002;39(4): 929-934.

40. Wolfe F, Zhao S, Pettitt D. Blood pressure destabilization and edema among 8538 users of celecoxib, rofecoxib, and nonselective nonsteroidal antiinflammatory drugs (NSAID) and nonusers of NSAID receiving ordinary clinical care. J Rheumatol. 2004;31(6): 1143-1151.

41. Aw TJ, Haas SJ, Liew D, Krum H. Meta-analysis of cyclooxygenase-2 inhibitors and their effects on blood pressure. Arch Intern Med. 2005;165(5):490-496

42. Sowers JR, White WB, Pitt B, Whelton A, Simon LS, Winer N, et al. The Effects of cyclooxygenase-2 inhibitors and nonsteroidal anti-inflammatory therapy on 24-hour blood pressure in patients with hypertension, osteoarthritis, and type 2 diabetes mellitus. Arch Intern Med. 2005;165(2):161-168. [erratum in Arch Intern Med. 2005;165(5):551].

43. Krum H, Swergold G, Curtis SP, et al. Factors associated with blood pressure changes in patients receiving diclofenac or etoricoxib: results from the MEDAL study. J Hypertens. 2009;27(4):886-893.

44. Andersohn F, Schade R, Suissa S, Garbe E. Cyclooxygenase-2 selective nonsteroidal anti-inflammatory drugs and the risk of ischemic stroke: a nested case-control study. Stroke. 2006;37(7):1725-1730.

45. Lee TA, Bartle B, Weiss KB. Impact of NSAIDS on mortality and the effect of preexisting coronary artery disease in US veterans. Am J Med. 2007;120(1):98.e9-e16.
46. Haag MD, Bos MJ, Hofman A, Koudstaal PJ, Breteler MM, Stricker BH. Cyclooxygenase selectivity of nonsteroidal anti-inflammatory drugs and risk of stroke. Arch Intern Med. 2008;168(11):1219-1224.

47. Nadareishvili Z, Michaud K, Hallenbeck JM, Wolfe F. Cardiovascular, rheumatologic, and pharmacologic predictors of stroke in patients with rheumatoid arthritis: a nested, case-control study. Arthritis Rheum. 2008;59(8):1090-1096.

48. Roumie CL, Mitchel EF Jr, Kaltenbach L, Arbogast PG, Gideon P, Griffin MR. Nonaspirin NSAIDs, cyclooxygenase 2 inhibitors, and the risk for stroke. Stroke. 2008;39(7):2037-2045.

49. Wilner KD, Rushing M, Walden C, Adler R, Eskra J, Noveck R, et al. Celecoxib does not affect the antiplatelet activity of aspirin in healthy volunteers. J Clin Pharmacol. 2002;42(9):1027-1030.

50. Cox ER, Frisse M, Behm A, Fairman KA. Over-the-counter pain reliever and aspirin use within a sample of long-term cyclooxygenase 2 users. Arch Intern Med. 2004;164(11):1243-1246.

51. Levesque LE, Brophy JM, Zhang B. The risk for myocardial infarction with cyclooxygenase- 2 inhibitors: a population study of elderly adults. Ann Intern Med. 2005;142(7):481-489.

52. Rahme E, Nedjar H. Risks and benefits of COX-2 inhibitors vs non-selective NSAIDs: does their cardiovascular risk exceed their gastrointestinal benefit? A retrospective cohort study. Rheumatology. 46(3):435-438.

53. Rahme E, Bardou M, Dasgupta K, Toubouti Y, Ghosn J, Barkun AN. Hospitalization for gastrointestinal bleeding associated with non-steroidal anti-inflammatory drugs among elderly patients using low-dose aspirin: a retrospective cohort study. Rheumatology. 2007;46(2):265-272.
Therapeutics and Clinical Risk Management

\section{Publish your work in this journal}

Therapeutics and Clinical Risk Management is an international, peerreviewed journal of clinical therapeutics and risk management, focusing on concise rapid reporting of clinical studies in all therapeutic areas outcomes, safety, and programs for the effective, safe, and sustained use of medicines. This journal is indexed on PubMed Central, CAS,

\section{Dovepress}

EMBase, Scopus and the Elsevier Bibliographic databases. The manuscript management system is completely online and includes a very quick and fair peer-review system, which is all easy to use. Visit $\mathrm{http} / / / \mathrm{www}$.dovepress.com/testimonials.php to read real quotes from published authors. 